\title{
Reported self-efficacy of nursing clinical instructors in a bachelor's of science in nursing program
}

\author{
Annette Ferguson*, Natalie Perry \\ School of Nursing, Marshall University, Huntington West Virginia, United States
}

Received: September 14, 2020

Accepted: November 8, 2020

Online Published: November 16, 2020

DOI: $10.5430 /$ jnep.v11n3p28

URL: https://doi.org/10.5430/jnep.v11n3p28

\begin{abstract}
Clinical instructors play a significant role in the development of safe and competent nursing students. When nurses beginning their career as a clinical instructor, a substantial gap in knowledge can existence in the expectations of this new role. A deficiency of formal education in nursing education or orientation to this position can lead to a lack of self-efficacy and knowledge among clinical instructors. Research supports that a formal orientation and training increases feelings of self-efficacy among clinical instructors. The purpose of this study was to evaluate an online educational program on clinical instructor's knowledge and self-efficacy towards teaching in a pre-licensure bachelors of science in nursing program. A pre-test/post-test design was utilized to assess changes in knowledge and self-efficacy immediately before and after the intervention for ten clinical instructors. Directly following the training, knowledge scores were measured with a statically significant result. In addition, immediately after the training and three months after the training, self-efficacy scores were measured and found to be statically significantly. In conclusion, the educational intervention was found to be statistically significant in improving the knowledge and self-efficacy scores among clinical instructors in the program as evidenced by the pre-test/post-tests results. This program was cost-effective to implement as there was no cost to the school of nursing or clinical instructors. The instructors could complete the online training from any location that had internet access and during any time of the day or night at their convenience.
\end{abstract}

Key Words: Clinical instructors, Online training, Self-efficacy, Nursing students

\section{INTRODUCTION}

Clinical instructors play a significant role in the development of safe and competent nursing students. Clinical opportunities provide an environment for nursing students to apply what they have learned in the lab and classroom to clinical practice. When a nurse clinician begins his or her career as a clinical instructor, he or she may not be aware of the different expectations and specialized skill set regarded for this new role. When an orientation to this position is not provided, this can lead to lack of self-efficacy among clinical instructors. According to Bandura, ${ }^{[1]}$ self-efficacy is one's belief in one's ability, or perceived ability, to function in a particular setting. Feelings of self-efficacy can be enhanced through the process of learning and achievement in a role. Therefore, providing formal orientation and training to clinical instructors is needed to better prepare them and increase feelings of self-efficacy in this new role.

According to the American Association of Colleges of Nursing, ${ }^{[2]}$ there is a shortage of nurse educators in the United States. There are many reasons identified by the AACN for the shortage of nursing faculty including an aging population with a wave of retirement in the next 10 years, limited number of nurses being admitted into graduate programs

\footnotetext{
*Correspondence: Annette Ferguson; Email: taylor171@marshall.edu; Address: School of Nursing, Marshall University, Huntington West Virginia, United States.
} 
due to the shortage of faculty and clinical sites, and higher salaries in the clinical and private sector enticing potential educators away from the academic setting. ${ }^{[2]}$ The shortage in nurse educators not only impacts the number of nursing faculty in the academic setting, but also impacts the number of clinical instructors available in the clinical setting. Clinical instructors teach students in the lab and/or hospital or other healthcare setting. They primarily work with students to refine and develop their clinical skills.

One strategy that many nursing programs are utilizing to deal with the shortage in nursing faculty is to hire adjunct clinical instructors. Typically, adjunct clinical instructors are hired on a per semester basis to provide clinical education and supervision to a group of nursing students while directly working with patients. The role of clinical instructors is to assist students with the integration of theoretical learning from the classroom and to apply this learning in the clinical practice setting. ${ }^{[3]}$ Adjunct clinical instructor are normally comfortable in their role as a bedside nurse, yet, may be uncomfortable with their new role as a clinical instructor. Educating nursing students requires a specialized skill set including the ability to provide constructive feedback, evaluating students fairly based on course objectives, and looking for learning opportunities that will promote critical thinking. It is essential that clinical instructors are provided with resources and training so they can be confident in this new role and can provide students with the best clinical experiences.

The purpose of the project was to develop and implement an online clinical instructor educational program in a prelicensure BSN program. The "Clinical Instructor Academy" (CIA) program was implemented to increase the knowledge and self-efficacy of clinical instructors regarding the school of nursing policies and procedures and teaching students in the clinical setting.

\subsection{Literature review}

To identify evidence to guide the development of the CIA, a literature review was conducted utilizing PubMed, Cochrane Collaborative, and Cumulative Index to Nursing and Allied Health Literature (CINAHL) databases. The key terms used included clinical instructor programs, clinical teaching strategies, clinical instructor self-efficacy, and clinical instructor perceived needs. Articles published after 2014 in English were retrieved to review. Literature on clinical instructors' perceived needs, clinical instructor self-efficacy, and clinical instructor programs were determined to be most important to this project.

In an integrated review conducted by McPherson, ${ }^{[4]}$ there was a review of nineteen articles for evidence of what is

Published by Sciedu Press needed for part-time clinical instructor to assume the role of a nurse educator. There were four major themes identified from the review of the literature. First, providing mandatory structured orientation is important to easing the transition of new part-time clinical faculty into the clinical educator role. Next, having an assigned mentor to meet frequently with the new part-time clinical instructor and provide feedback helps to build a relationship. By building this relationship, the new clinical instructor will have support in this new role. Finally, having good communication with the nursing program provides a sense of connection that is important for both recruitment and retention of part-time clinical instructor. Limitations to the integrated review included the focus on only part-time clinical faculty instead of all clinical faculty and restricting selection of articles between 2013 and 2018; older literature may have provided valuable insight. Some weaknesses identified in the selected article in the review were convenience sampling, unreported reliability and validity of instruments, limited generalizability, small sample sizes, low response rates, and qualitative responses. Overall, the strength of the evidence in the integrated review was reported as weak to moderate.

Glynn, Kelsey, Taylor, Lynch, and DeLibertis ${ }^{[5]}$ conducted a survey design study with the purpose to identify the demographics of clinical instructors and the perceived learning needs and instructional support identified as success factors by adjunct clinical instructors. This study was conducted with sixty-one clinical adjunct nursing instructors in a Northeastern College. For the topic of perceived support from the academic institution, the findings showed that $56.1 \%$ acknowledged full support in their efforts and $81 \%$ reported multiple contacts during the semester with course coordinators. The lack of clinical instructor evaluations was noted by many respondents. Respondents stated the importance of feedback from the course coordinators related to their clinical instruction and the need for constructive measures to improve the clinical experience for their students. The participants overwhelmingly acknowledged the perceived benefits of a clinical faculty orientation program. Eighty-one percent believed that a structured orientation program would be of value and could improve the role of adjunct clinical nursing instructor. The respondents identified legal and ethical issues, reflective practice, and informatics as priority topics. The topics of teaching and learning theory, core competencies, and grading assignment received the lowest rating for incorporation into a clinical faculty orientation program. A few limitations of the study included qualitative design, open-ended response questions, and lack of formal validity/reliability testing prior to administration of the survey. In addition, 230 surveys were emailed to eligible participants 
with only 61 participants completing the survey, a response rate of $27 \%$.

Suplee, Gardner, and Jerome-D'Emilia ${ }^{[6]}$ conducted a study with the aim to describe the preparation for clinical instruction and experiences of faculty who teach nursing students, identify the range of student challenges that faculty encounter and their level of comfort in managing these challenges. Seventy-four nursing faculty members completed a fourteen item questionnaire. The results of the study for educational preparation and development included 57\% attending conferences, 53\% receiving an orientation to clinical teaching, and $31 \%$ reported no preparation. For faculty development, $49 \%$ of participants reported receiving an evaluation of their skills, $46 \%$ were offered an opportunity to attend workshops, $28 \%$ were provide with reading materials, $32 \%$ reviewed peer evaluation, and $16 \%$ reported no faculty development was offered. Regarding educational knowledge and skills the participants reported learning about how to document student progress $(61 \%)$, how to teach students to think critically (58\%), and how to make clinical assignments (47\%). The least learned topics included how to work with students with physical, learning, or emotional disabilities, how to work with excellent students, how to manage legally mandated student learning accommodations, and how to manage incivility. Limitations of the study were the use of a convenience sample of participants that were recruited from a professional development conference for nursing faculty, therefore sample biasing was a possibility. Also, the sample was small (n $=74$ ) and the characteristics of the participants such as age, level of education, and years of teaching experience were not measured and may have influenced the findings.

Kim and $\operatorname{Shin}^{[7]}$ conducted a study using a cross-sectional design to determine the factors that impact nurses' teaching efficacy in clinical instruction. The researchers defined teaching efficacy as the belief in which the teacher can influence student learning. Teaching efficacy, general characteristics, and perception of clinical practice education were collected via self-reported questionnaires for 263 nurses at two hospitals. The results of this study found that teaching efficacy was greater for nurses in their 40's with more than 10 years of clinical practice. Furthermore, those with a leadership position in nursing such as a head or charge nurse had greater teaching efficacy scores as well as those with a master's degree in nursing. In addition, those with experience in teaching clinical practice and who had received clinical practice education had greater teaching efficacy. The strongest positive effect on teaching efficacy was length of clinical experience and work satisfaction. Based on these findings, the researchers recommended that nursing schools and hospitals develop educational opportunities for clinical instructors by providing orientation and faculty development programs that will enhance teaching efficacy and promote role satisfaction.

Rice $^{[8]}$ developed a program to increase clinical nurses' knowledge and skills for the new role as an adjunct clinical instructor. Twelve adjunct nursing faculty members from a large city in the United States completed the pre-test/posttest design study. The program was a one day, face-to-face seminar with content focusing on the collaborative process, curriculum development and planning, teaching strategies, clinical scholar support, and future program considerations. Limitations to the study included having a low number of adjunct faculty members attend the program and having both tenured and non-tenured faculty participate in the program. The study found that faculty members reported the presentations to be useful and meaningful as a professional development activity and had increased knowledge after the program.

Roman ${ }^{[9]}$ conducted a study with the purpose of determining if a professional development learning community would enhance the teaching capabilities of novice and experienced clinical instructors by improving their knowledge, confidence, teaching effectiveness, and feedback abilities. An eighteen question electronic survey was sent to thirty-seven clinical instructors who completed online learning modules and a discussion board. The modules included content related to teaching philosophy, instructional methods, providing feedback and evaluations, managing students who display unprofessional or inappropriate behaviors, teaching students with different learning styles, and knowledge of school and hospital policies. The results of the survey found significant change in the participants' self-reported knowledge of clinical teaching, providing feedback, and knowledge of both nursing school and hospital policies governing student clinical experiences. Limitations of the study included the small sample size $(n=37)$, the possibility of demand bias that may have inflated the pretest and posttest scores, and lack of a longitudinal analysis to determine the effects of the intervention on the outcomes over a period of time. Overall, participants had favorable comments regarding the learning community and professional development content.

Weston ${ }^{[10]}$ conducted a study with the purpose to determine whether the development and the introduction of an online clinical instructor program would be helpful in improving feelings of efficacy for nurse clinicians who were experienced clinical instructors or who were new to the role of clinical instructor. Thirty-five clinical instructors, both experienced and novice, completed the Self-Efficacy Toward Teaching Inventory (SETTI) tool to measure feelings of efficacy before and after completing the online training program. 
The program consisted of six online modules where participants took a pretest, review the modules, and then responded to the posttest. The content for the modules focused on instructional methods, building strong relationships with students, curriculum/course overview, selecting clinical assignments, clinical teaching strategies, and evaluation of clinical performance. Both groups, experienced and novice instructors, demonstrated significant improvement in self-efficacy and understanding of the role of a clinical instructor. Overall scores revealed that the novice instructor scores improved $89 \%$ after participation in the program. The experienced instructors showed a greater improvement of $98 \%$ regarding self-efficacy following the program. In addition, experienced instructors showed a more appreciable improvement than novice instructors in the areas of self-efficacy, role, understanding of content, and understanding of strategies. A few limitations of the study included small sample size $(n=35)$ and an unequal number of novice and experienced instructors participating the study. In additional, not all research questions were answered by all participants.

In summary, the studies reviewed indicated that part-time, adjunct clinical instructors have several perceived needs for the new role as a clinical instructor ${ }^{[4-6]}$ and, that clinical instructor programs are essential to increase knowledge, efficacy, and retention of adjunct nursing clinical instructors. ${ }^{[7-10]}$ Based on the evidence from the literature review, the CIA was developed and implemented to educate and prepare both experienced and new clinical instructors at a pre-licensure BSN program in the eastern US.

\subsection{Conceptual framework}

Knowles' Andragogy Learning Theory was the conceptual framework utilized to develop the CIA. Andragogy refers to a theory of adult learning that differs from how children learn. ${ }^{[11]}$ There are six core assumptions of this theory related to the program.

The first assumption is that the learner needs to know. Adjunct clinical instructors have knowledge on how to care for patients and this program would provide them with new knowledge for their role as a clinical instructor. This information would focus on teaching and learning strategies and evaluation techniques in the clinical setting. The second assumption is the self-concept of the adult learner. With additional training and education, the learner will have increased self-concept as a clinical instructor. This will directly be measured by utilizing a survey tool. The third assumption is the prior experience of the learner. The CIA takes into account the participants' prior knowledge as a nurse and builds on this with new knowledge for the role as a clinical instructor. The fourth assumption is the learners' readiness to

Published by Sciedu Press learn. Research supports that new adjunct clinical instructors have a desire for better understanding of their new role as a clinical instructor. The fifth assumption is orientation to learning. The program will focus on introducing the clinical instructor to their new role with information about the nursing program, teaching strategies, how to provide feedback and evaluation, and dealing with difficult clinical situations. The sixth, and final, assumption is the motivation to learn. Each participant who completes the training modules will be better prepared to perform as an adjunct clinical instructor, which should motivate them to learn.

\section{MethodS}

\subsection{Sample and setting}

The study participants were selected from a convenience sample of 22 pre-licensure BSN clinical instructors at a mediumsized university in the eastern US. All full-time BSN faculty and adjunct clinical instructors who teach students in the clinical setting were invited and encouraged to participate in the educational course offered online through the University's online learning management system. A total of ten clinical instructors participated ( $45 \%$ of those who were invited).

\subsection{Design and intervention}

The CIA was offered through the University's Blackboard learning management system and consisted of four modules that were progressively completed after the module quiz was complete. There was a brief introduction that outlined the content and objectives for the program. Module one consisted of a curriculum overview of the program including end of program student learning outcomes (EPSLOs) and curriculum sequence. Module two reviewed clinical specific information found in the faculty and student handbooks such as the policy for cancelling clinical, dress code and cell phone policy. Module three provided an overview of information specifically regarding the clinical environment including clinical instructor expectations, making student assignments and grading clinical paperwork. Module four discussed challenging situations that may occur and ways to manage those situations such as student anxiety, learning disabilities and those who are clinically unsatisfactory. Ensemble voice recordings were completed for the introduction and each module for clinical instructors to view. Each module would take approximately 10-15 minutes to complete (including the module post-test).

A pre-test/post-test design was utilized for this study. The study evaluated the implementation of an online educational program based on the school of nursing's policies and procedures as well as identified areas of concern based on feedback from students and clinical instructors and research. The 
educational program was developed into four online learning modules with voice over presentation and student work examples. Topics covered in the presentation included a curriculum overview, faculty and student handbooks, the clinical environment, and challenging situations. All clinical instructors within the program were added to the online course titled "Clinical Instructor Academy" through the university's Blackboard site. Participation was encouraged for all fulltime and part-time clinical instructors through face-to-face and email communications.

The knowledge-based quiz consisted of fifteen items based on topics covered in the four modules. The knowledge-based questions were in a multiple choice or true/false format. The questions were created by the researchers based on the module content and program objectives. An independent senior nursing faculty member verified the accuracy of the questions and answers. This knowledge-based quiz was given directly before the start of the modules to serve as the baseline pretest. The knowledge-based quiz questions were integrated throughout the modules to measure the post-test knowledge of the participants.

The evaluation tool utilized to measure the participants feeling of self-efficacy was a modified SETTI survey. ${ }^{[10]}$ The researchers of this project received permission from Weston to utilize the thirty-nine item modified SETTI survey tool to evaluate program outcomes regarding clinical instructors' feelings of self-efficacy in regard to clinical instruction. The inventory items were based on identified areas where selfefficacy could be lacking in relation to clinical instruction. The participants were asked to rank the questions on a Likert scale of 1 to 4 ( 1 being not confident and 4 being completely confident). The SETTI survey had a reported face validity and an internal consistency reliability of $0.654 .{ }^{[10]}$ The SETTI survey tool was administered directly before, immediately after the online educational modules were completed, and at the end of the semester or three months after the initiation of the program to determine long-term effects of the educational training.

\subsection{IRB submission process}

Before implementation of the program, approval from the institutional review board (IRB) was received from the University where the School of Nursing was located. In addition, a letter of support from the Director of Nursing program was obtained for the implementation of the online educational training program.

\subsection{Data collection}

A demographic survey, knowledge-based quiz, and the SETTI survey tool were used in the online format before the educational modules were completed to collect baseline data. While completing the program, the knowledge-based questions were integrated throughout the modules. At the end of the final module, the SETTI post-test survey was administered again. Near the end of the semester, participants were asked to complete the SETTI survey for a third and final time three months after the initiation of the program. All quizzes and surveys were administered in an online format. Participants were randomly assigned numerical identifiers in order to preserve confidentiality. The data was coded by scoring the quiz as a total number of questions correctly answered. Each SETTI question was individually viewed for each participant and the response for the questions were numerically coded as either $0,1,2$, or 3 based on the participants response. The demographic data was also coded numerically in order to be adequately analyzed.

\subsection{Data analysis}

Data was analyzed using SPSS $₫$ version 25 software. The demographic information was analyzed using descriptive statistics. The differences between the pre-test and post-tests total knowledge-based quiz scores and the SETTI survey were analyzed using paired sample $t$-test.

\section{RESUltS}

A total of ten clinical instructors participated in the online modules and completed the pre- and post-tests knowledgebased quiz and SETTI survey. The majority of participants were female (90\%) with the majority $(90 \%)$ having over ten years of experience as a registered nurse. Eighty percent of participants had over six years of teaching experience. All of participants, but one had a minimum of a master's degree in nursing or higher (see Table 1).

A paired sample $t$-test (see Table 2) was conducted to evaluate the impact of the online learning modules on the clinical instructors' knowledge scores. The clinical instructors' mean knowledge scores increased significantly from pre-test quiz $(12.6 \pm 1.17)$ to the post-test quiz (14.4 \pm 0.69$), t(-5.51)$ $=9, p=.000$ (two-tailed). The mean increase in the survey scores were 1.80 with a $95 \%$ confidence interval ranging from -2.53 to -1.06 . The eta squared statistic (0.77) indicated a large effect size for the educational program.

The SETTI survey scores were calculated at three different time periods. The first time period was immediately before the online learning modules were viewed. The second time was after completion of the entire online learning modules. The third time was at the end of the academic semester or within three months after completion of the online learning modules. During the first time period, before implementation of the online learning modules, the SETTI survey mean 
scores were 98.7. During the second time period, after completion of the online learning module, the SETTI survey mean scores were 109.6. During the third time period, within three month period or at the end of the academic semester, the SETTI survey mean scores were 110.90 .

Table 1. Demographic characteristics of participants $(n=$ 10)

\begin{tabular}{|c|c|c|}
\hline Variable & Frequency & Percentage (\%) \\
\hline \multicolumn{3}{|l|}{ Gender } \\
\hline Female & 9 & 90 \\
\hline Male & 1 & 10 \\
\hline Total & 10 & 100 \\
\hline \multicolumn{3}{|c|}{ Years as Registered Nurse } \\
\hline 0 to 9 & 1 & 10 \\
\hline 10 to 19 & 4 & 40 \\
\hline 20 to 29 & 1 & 10 \\
\hline 30 or longer & 4 & 40 \\
\hline Total & 10 & 100 \\
\hline \multicolumn{3}{|c|}{ Years as Nurse Educator } \\
\hline 1 or less & 1 & 10 \\
\hline 2 to 5 & 1 & 10 \\
\hline 6 to 10 & 3 & 30 \\
\hline 10 or more & 5 & 50 \\
\hline Total & 10 & 100 \\
\hline \multicolumn{3}{|c|}{ Degree/Level of Education } \\
\hline DNP & 3 & 30 \\
\hline EdD & 3 & 30 \\
\hline $\mathrm{MSN}^{*}$ & 2 & 20 \\
\hline Other & 1 & 10 \\
\hline FNP & 1 & 10 \\
\hline Total & 10 & 100 \\
\hline
\end{tabular}

Table 2. Paired sample $t$-test on pre and post-test knowledge scores on online learning modules $(\mathrm{n}=10)$

\begin{tabular}{lllll}
\hline $\begin{array}{l}\text { Clinical } \\
\text { Practice }\end{array}$ & $\begin{array}{l}\text { Pre- } \\
\text { education }\end{array}$ & $\begin{array}{l}\text { Post- } \\
\text { education }\end{array}$ & $\begin{array}{l}\text { Paired } \\
\boldsymbol{t} \text { Knowledge }\end{array}$ & $\boldsymbol{p}$ \\
\cline { 2 - 4 } & Mean \pm SD & Mean \pm SD & & \\
\hline $\begin{array}{l}\text { Participants } \\
\text { total scores }\end{array}$ & $12.6 \pm 1.17$ & $14.4 \pm 0.69$ & -5.51 & .000 \\
\hline
\end{tabular}

Note. Magnitude of effect was large, eta-square $=.77$

A paired sample $t$-test (see Table 3) was computed to compare the mean SETTI survey scores at time period 1 and 2. There was a significant difference in mean SETTI survey scores before the intervention (time period 1) (98.7 \pm 13.7) and immediately after the intervention (time period 2) $(109.6 \pm 5.87) ; t(-2.89)=9, p=.018$, two-tailed). In addition, the magnitude of effect was large (eta squared $=.48$ ), demonstrating clinical significance for the training program.

A paired sample $t$-test (see Table 4) was computed to com- pare the mean SETTI survey scores at the first and third time that the survey was completed. This was measured to determine if the participants maintained a change in self-efficacy over a period of three or more months. There was a significant difference in mean SETTI survey scores before the intervention (first survey) $(98.7 \pm 13.7)$ and three months after the intervention (third survey) $(110.9 \pm 6.20) ; t(-2.64)$ $=9, p=.027$, two-tailed). In addition, the magnitude of effect was large (eta squared $=.43$ ), demonstrating clinical significance.

Table 3. Paired sample $t$-test comparison of mean setti survey scores for time period 1 and time period $2(n=10)$

\begin{tabular}{llllll}
\hline \multirow{2}{*}{$\begin{array}{l}\text { SETTI } \\
\text { Survey }\end{array}$} & Time Period (1) & Time Period (2) & Paired & $\boldsymbol{p}$ \\
\cline { 2 - 3 } $\boldsymbol{t}$ test & Mean \pm SD & Mean \pm SD & & \\
\hline $\begin{array}{l}\text { Participants } \\
\text { total scores }\end{array}$ & $98.7 \pm 13.71$ & $109.6 \pm 5.87$ & -2.89 & .018 \\
\hline \multicolumn{1}{l}{ Note. Magnitude of effect was large, eta-square $=.48$} & &
\end{tabular}

Table 4. Paired sample $t$-test comparison of mean setti survey scores for time period 1 and time period $3(n=10)$

\begin{tabular}{|c|c|c|c|c|}
\hline \multirow{2}{*}{$\begin{array}{l}\text { SETTI } \\
\text { Survey }\end{array}$} & Time Period (1) & Time Period (3) & \multirow{2}{*}{$\begin{array}{l}\text { Paired } \\
t \text { test }\end{array}$} & \multirow{2}{*}{$p$} \\
\hline & Mean \pm SD & Mean \pm SD & & \\
\hline $\begin{array}{l}\text { Participants } \\
\text { total scores }\end{array}$ & $98.7 \pm 13.71$ & $110.9 \pm 6.20$ & -2.64 & .027 \\
\hline
\end{tabular}

Note. Magnitude of effect was large, eta-square $=.43$

\section{Discussion}

The addition of adjunct clinical instructors are essential to meet the needs of nursing programs. Without the use of these supplemental instructors, many nursing programs would be forced to turn away qualified nursing students. Unfortunately, many clinical instructors do not receive adequate training to prepare them for their new role as a clinical instructor. ${ }^{[6]}$ Based on the research, several topic areas were identified by adjunct clinical instructors to include into an educational training program. ${ }^{[4-8]}$ Compared to studies reviewed in the literature, this project supports the need for clinical instructors to receive educational training on their role as a clinical instructor. The first goal was to determine if an online educational program would increase the knowledge of clinical instructors regarding policy and procedures related to clinical instruction, clinical environment, and how to handle challenging situations in the clinical environment. All of the topics included within the training modules were based on the research findings and feedback from previous adjunct clinical instructors. ${ }^{[4-8]}$ The knowledge test scores were analyzed using a paired $t$ test. The pre/post-test results found that the online training program did improve the clinical instructors' knowledge in all areas being measured. The findings are consisted with previous studies in the literature where there 
was an improvement in overall knowledge regarding clinical instruction.

Many practicing nurses have a strong sense of self-efficacy in their role as a bedside nurse, yet may have little sense of self-efficacy in their role as a clinical instructor. ${ }^{[9]}$ For an adjunct clinical instructor to obtain self-efficacy they need a clear understanding of this new role. Another goal of the project was to improve feelings of self-efficacy among the participants by providing training on clinical instruction. The SETTI survey tool was utilized to measure the clinical instructors' feelings of self-efficacy. The SETTI survey results were measured at three different periods of time: before the beginning of the online training program, immediate after completing the training course, and three months later (at the end of the semester). The initial launch of the program was prior to the start of the semester so that all participants could participate before clinicals began. Participants' scores for the pre and posttest SETTI were analyzed using a paired $t$ test. The results from the SETTI survey found that clinical instructor's self-efficacy was improved and maintained three months later. These finding are consistent with Weston ${ }^{[9]}$ study where both novice and experienced clinical instructors self-efficacy improved after completing a clinical instructor training program.

This program was offered in an online format that allowed clinical instructors to complete at any time or location as long as they had internet access. All participants had access to internet either at home or work. The modules were self-paced with voice over presentations. Participants were able to start and stop the presentations at any time as needed. Each module was approximately 10-15 minutes in length with a few of the knowledge-based questions at the end of each module. The entire program could be completed within an hour and a half. Participants continued to have access to the program material throughout the entire semester.

With budget cuts at both the national and state levels many nursing programs have found it necessary to develop training programs with limited financial resources. The cost of the CIA training program was minimal with only the researchers' time being a factor. The program was developed, implemented, and evaluated within a nine-month period. Since, the program was uploaded to a Blackboard learning man-

\section{REFERENCES}

[1] Bandura A. Self-efficacy: Toward a unifying theory of behavioral change. Psychological Review. 1977; 84: 191-215. https: //doi.org/10.1037/0033-295X.84.2.191

[2] American Association of Colleges of Nursing. Nurs34 agement system the modules can easily be modified by the researchers as needed for new clinical instructors in the future.

There were a few limitations to the project. The pre-test/posttest knowledge-based quiz utilized to measure the clinical instructors' knowledge was created by the researchers and did not have any documented reliability prior to the study. The quiz questions were reviewed by an experienced faculty within the program prior to administration of the study to verify accuracy. Another limitation was that only ten out of twenty-two (45\%) clinical instructors completed the educational program. Several efforts were made by the project leaders to have all clinical instructors complete the program such as email and face-to-face reminders. Providing an incentive such as continuing education credit (CEU) or a certificate of completion in the future may encourage participation of clinical instructors. The last limitation was that the results may not be generalized to other schools of nursing. This project was conducted at a single site in a medium-sized university setting in a pre-licensure BSN program. Regardless of the limitations mentioned, the overall results of the project were encouraging with an increase in clinical instructors' knowledge and feelings of self-efficacy in clinical instruction.

\section{Conclusion}

In conclusion, the CIA online educational program was found to significantly improve knowledge and feelings of self-efficacy among clinical instructors within a pre-licensure BSN program as evidenced by the pre-test/post-test knowledge quiz and SETTI survey results over a three month period of time. The program was convenient for clinical instructors in the online format and was cost effective for the nursing program to implement. The project supports the need for nurses new to clinical instruction to receive orientation and training for their role as nurse educators.

\section{ACKNOWLEDGEMENTS}

The authors expresses their appreciation to the adjunct nursing instructors who participated in this study and were willing to complete the survey tools.

\section{CONFlicts OF INTEREST Disclosure}

The authors declare that there is no conflict of interest. ing faculty shortage. 2019. Available from: https: //www . aacnnursing . org/news-information/fact-she ets/nursing-faculty-shortage

[3] Bolton K. Effects of an online education program on self-efficacy and knowledge of the clinical teacher role: A study with nursing 
clinical instructors. (Master's Thesis). 2011. Retrieved from Queens University. Kingston Ontario, Canada.

[4] McPherson A. Part-time clinical nursing faculty needs: An integrated review. Journal of Nursing Education. 2019; 58(4): 201-206. PMid:30943294 https://doi.org/10.3928/01484834-20190 321-03

[5] Glynn DM, Kelsey W, Taylor M, et al. Nursing clinical instructor needs assessment. Journal of Nursing and Care. 2014; 3: 3.

[6] Suplee PD, Gardner M, Jerome-D'Emilia B. Nursing faculty preparedness for clinical teaching. Journal of Nursing Education. 2014; 53(3): S38-S41.

[7] Kim E, Shin S. Teaching efficacy of nurses in clinical practice education: A cross-sectional study. Nurse Education Today. 2017; 54: 64-
68. PMid:28486157 https://doi.org/10.1016/j.nedt. 2017. 04.017

[8] Rice G. An orientation program for clinical adjunct faculty. The ABNF Journal. 2016; winter 7-10.

[9] Roman T. Novice and expert clinical instructors: A method to enhance teaching capabilities. Nursing Education Perspectives. 2018; 39(6): 368-370. PMid:29624518 https://doi .org/10.1097/01 .NEP. 0000000000000293

[10] Weston J. The clinical instructor program: Improving self-efficacy for nurse educators. Nurse Educator. 2018; 43(3): 158-161. PMid:28857957 https://doi.org/10.1097/NNE. 0000000000 000452

[11] Knowles M. The modern practice of adult education: from pedagogy to andragogy. New York: The Adult Education Company. 1980. 